\title{
Consuming media, consuming food: investigating concurrent TV viewing and eating using a $7-d$ time use diary survey
}

\author{
Monique C Alblas ${ }^{1, *} \odot$, Saar Mollen ${ }^{1}$, Annemarie M Wennekers ${ }^{2}$, Marieke L Fransen ${ }^{3}$ \\ and Bas van den Putte ${ }^{1}$ \\ ${ }^{1}$ Amsterdam School of Communication Research (ASCoR), University of Amsterdam, P.O. Box 15791, 1001 NG \\ Amsterdam, The Netherlands: ${ }^{2}$ Netherlands Institute for Social Research (SCP), Den Haag, The Netherlands: \\ ${ }^{3}$ Communication and Media, Behavioural Science Institute (BSI), Radboud Universiteit, Nijmegen, The Netherlands
}

Submitted 25 February 2021: Final revision received 18 May 2021: Accepted 28 June 2021: First published online 21 July 2021

\begin{abstract}
Objective: One explanation for the relationship between TV viewing and obesity is that people may (over)eat while watching TV. The current study investigated associations between TV viewing and the time spent on (concurrent) eating in a naturalistic setting among a general population sample.

Design: Preregistered secondary data analyses were performed of a diary survey in which respondents reported their time use in 10-min blocks for $7 \mathrm{~d}$.

Setting: Concurrent TV viewing and eating was operationalised as all blocks in which TV viewing and eating occurred simultaneously. Furthermore, the TV content respondents watched was coded as food-related (i.e. culinary content) or nonfood related.

Participants: The sample composed of 2292 adults (58.9\% female) in the Netherlands, aged $\geq 20$ years, from all educational levels (18.1\% low, $29 \cdot 8 \%$ middle and $51.4 \%$ high).

Results: More than half of the respondents (51.3\%) reported concurrent TV viewing and eating at least once during the 7 -d diary period. The average eating occasion was longer in duration while watching TV ( $v$. without media use), and the total time spent on eating was longer on days of concurrent TV viewing and eating ( $v$. days of eating without media use). The percentage of TV viewing time spent on concurrent eating did not differ between food-related and non-food-related TV content.

Conclusions: Eating while watching TV was related to an increased time spent on eating. Even though energy intake was not assessed, these findings from a naturalistic setting provide further evidence that concurrent TV viewing and eating may contribute to overeating.
\end{abstract}

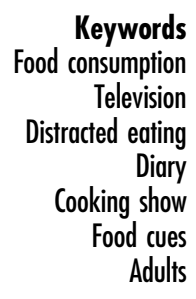

The relationship between screen time and the development of obesity has been widely investigated over the past decades, and particularly TV viewing has been identified as an important contributor to weight gain ${ }^{(1-3)}$. One plausible explanation for this is that many people may (over) eat while watching $\mathrm{TV}^{(4)}$. First, this may occur because the mere activity of TV viewing triggers the intake of food and beverages (hereafter collectively referred to as eating), for example due to distraction or habit ${ }^{(5,6)}$. Second, the frequent exposure to food cues on TV, such as in commercial blocks and cooking shows, may elicit cravings for food which may subsequently result in eating ${ }^{(5,7)}$.
Experimental studies have reported evidence for both of these notions ${ }^{(6,8-10)}$, but the vast majority of research on concurrent TV viewing and eating has been conducted in controlled laboratory settings and among either children or (predominantly female) student samples. Studying eating while watching TV in daily life, and in the general population of adults, provides a more ecologically valid view on this behaviour. Using a 7-d time use diary survey among a large sample ( $n$ 2292) of the general population of adults in the Netherlands, the current study provides further understanding of how TV viewing is associated with eating behaviour in daily life. 


\section{Concurrent TV viewing and eating}

Prior research has often reported a positive association between the amount of TV viewing and overall energy intake $e^{(1,11,12)}$. It is likely that this relationship may at least be partly explained by eating while watching $\mathrm{TV}^{(1,12)}$, but to gain insight into the potential impact of this behaviour, it is important to first examine the extent to which people actually engage in concurrent TV viewing and eating in daily life. Although research on the prevalence of concurrent TV viewing and eating is scarce, some efforts have previously been made to study this behaviour ${ }^{(13-17)}$. For example, in a sample of obesity-treatment seeking women with overweight, it was found that $46 \%$ of meals were consumed in front of the $\mathrm{TV}^{(15)}$. Furthermore, Stroebele and De Castro $^{(13)}$ found that among (predominantly female) undergraduate students, on average one meal per day was eaten with the TV on. Although these studies provide some indication that combining TV viewing and eating is common, this remained to be studied among the general population of adults. The following research question was therefore posed:

\section{RQ1}

What is the time spent on concurrent TV viewing and eating among adults in the Netherlands?

Results from experimental studies typically show that when eating in front of the TV, people eat more - as demonstrated by a higher energy intake - than when eating without watching $\mathrm{TV}^{(6,18-20)}$. This may be the result of several mechanisms, such as distraction ${ }^{(4-6)}$, learned associations between TV viewing and eating resulting from repeatedly pairing these two behaviours in the past ${ }^{(6,21)}$ or a positive mood induced by TV viewing ${ }^{(6,22)}$. Importantly, eating while watching TV likely contributes to an overall increase in (the time spent) eating across the day and is thus not compensated for during another moment. A study by Stroebele and De Castro ${ }^{(13)}$ showed that on days of eating with the TV on ( $v$. off), participants (i.e. undergraduate students) ate more meals, resulting in an overall higher energy intake on those days. Furthermore, experimental research showed that consuming a fixed amount of food while watching TV $(v$. without watching TV) resulted in additional eating later on the day, likely because focusing on the TV content impaired one's memory and vividness of the eating episode ${ }^{(9,23,24)}$ and less reduction in experienced satiety after distracted ( $v$. nondistracted) eating ${ }^{(25)}$. In line with these findings primarily stemming from research in laboratory contexts, it was expected that eating while watching TV would be positively associated with increased eating, reflected by more time spent on eating. Prior research indicates that the time spent on eating predicts energy intake ${ }^{(20,26-28)}$ as well as $\mathrm{BMI}^{(29)}$. For instance, Pliner and colleagues ${ }^{(26)}$ experimentally manipulated eating duration and found that a longer
( $v$. shorter) eating duration while being distracted increased food intake, most likely due to a prolonged opportunity to eat ${ }^{(5)}$. The following hypotheses were therefore proposed:

\section{H1a}

The average time spent on an eating occasion is longer when eating while watching TV compared with eating without watching TV or using other media.

\section{H1b}

The total time spent on eating is longer on days of concurrent TV viewing and eating compared with days of eating without TV viewing or using other media.

\section{The role of exposure to food cues in TV content}

In addition to the activity of TV viewing, the content of TV, i.e. exposure to food cues, has also been proposed as an important contributor to increased eating and subsequent weight gain $^{(5,7,30)}$. Food is widely portrayed on TV, for example, in commercial blocks but also in other ways such as in culinary content $^{(31,32)}$. Such palatable, but often unhealthy food cues on TV may function as external primes that trigger eating, even in the absence of physical hunger ${ }^{(33)}$. Consistent with this, several experimental studies reported that watching food-related (v. non-food-related) TV content resulted in increased food intake $^{(8,10,34)}$, although it should be noted that other research found no evidence for such an effect ${ }^{(35-37)}$ or reported mixed results within studies, often depending on individual differences ${ }^{(38,39)}$. In naturalistic settings, there has also been some evidence for a positive association between exposure to food cues on TV and increased eating ${ }^{(40-42)}$, but these studies assessed overall eating behaviour across the day. To our knowledge, no research in a naturalistic setting has investigated watching food-related TV content and concurrent eating, which would provide insight into the immediate relationship between exposure to food on TV and eating. Based on the discussed research, and consistent with the wider food cue reactivity literature showing that exposure to the sight of food triggers eating (for a review, see ${ }^{(43)}$ ), it was expected that watching food-related (i.e. culinary) TV content would be positively associated with increased concurrent eating. Again, increased eating is operationalised as the time spent on eating, this follows from prior research showing that the time spent eating predicts energy intake ${ }^{(20,26-28)}$ :

\section{H2}

A longer time is spent on concurrent TV viewing and eating when watching food-related TV content, compared with non-food related TV content, relative to the total viewing time of these content types. 


\section{Exploring the influence of demographic characteristics}

Even though TV viewing may be associated with increased eating for many people, it has been suggested that some individuals may be more susceptible to environmental cues than others ${ }^{(4,21,44)}$. In this regard, demographic characteristics have been identified to potentially play an important role, yet the influence of these variables is underexplored $^{(4,44)}$. The vast majority of research on (concurrent) TV viewing and eating has been conducted among young, highly educated and predominantly female samples, and thus, to date it remained to be studied whether similar results would be obtained for older, less educated and male samples. This is particularly important because a higher age and a lower educational level are (independently) associated with obesity ${ }^{(45,46)}$ which indicates that for some of these groups concurrent TV viewing and eating may be particularly harmful. To identify populations that may be more prone to (the influences of) concurrent TV viewing and eating, the present study explored the potential role of age, gender and educational level in concurrent TV viewing and eating through the following research question:

\section{RQ2}

To what extent do demographic characteristics (i.e. age, gender and educational level) influence the prevalence of concurrent TV viewing and eating (as proposed in RQ1) and the expected relationships between TV viewing and concurrent eating (as proposed in H1a, H1b and H2)?

\section{Methods}

\section{Data collection and procedure}

The study's protocol was preregistered on Open Science Framework (https://osf.io/vp64a). Secondary data analyses were conducted based on a time use survey (Media: Time) that aims to capture media use among people aged 13 years and older in the Netherlands ${ }^{(47)}$. The data used for the present study were collected between 10 September and 24 October 2018 by research company GfK Market Research at the request of the Netherlands Institute for Social Research (SCP) and several audience measurement organisations in the Netherlands. Respondents were recruited via e-mail, telephone or mail (after providing their contact details in previous research on media use). They were first asked to complete a questionnaire assessing demographic characteristics and several other individual characteristics. Next, respondents were instructed to register all activities that they engaged in for at least $5 \mathrm{~min}$ in an online diary during seven consecutive days (the starting day was randomly assigned), either by completing the diary themselves or via a daily telephone call with an
Table 1 The distribution of demographic characteristics in the sample

\begin{tabular}{lcc}
\hline & $n$ of respondents & $\%$ of total sample $(n$ 2292) \\
\hline Age & & \\
20-34 years old & 522 & $22.8 \%$ \\
35-49 years old & 672 & $29.3 \%$ \\
50-64 years old & 647 & $28.2 \%$ \\
65+ years old & 451 & $19.7 \%$ \\
Gender & & \\
Male & 943 & $41.1 \%$ \\
Female & 1349 & $58.9 \%$ \\
Educational level & & \\
Low & 416 & $18.1 \%$ \\
Middle & 683 & $29.8 \%$ \\
High & 1177 & $51.4 \%$ \\
Unknown & 16 & $0.7 \%$ \\
\hline
\end{tabular}

interviewer who filled in the diary for them. For every block of $10 \mathrm{~min}$, respondents registered one general activity (e.g. sleeping, working, eating and drinking, household chores and personal care) and if applicable up to three media activities (e.g. TV viewing, reading a book and social media use), all according to pre-defined categories. Respondents who completed the study received a financial compensation of 30 euro.

\section{Respondents}

After excluding respondents whose diary did not meet basic requirements $\left(\mathrm{see}^{(47)}\right)$, the sample consisted of 2655 respondents. For the current study, non-adult respondents were excluded (i.e. respondents in the age group $13-19, n 150$ ), as well as respondents who did not complete the survey on all $7 \mathrm{~d}(n$ 60) and respondents with extreme scores on the dependent variables (see Analyses section; $n$ 153) This led to a final sample size of 2292 respondents (see Table 1 for the distribution of demographic characteristics in the sample).

\section{Measures}

(Concurrent) TV viewing and eating

TV viewing was operationalised as every 10-min block in which a respondent reported watching TV content. This could be TV content watched at the moment of broadcasting, TV content watched at another moment (e.g. a prerecorded TV program) or watching other bought, streamed or downloaded content (e.g. via Netflix). Eating was operationalised as every 10-min block in which food and beverage intake was reported, which was defined as consuming meals and snacks, except for going out for food (e.g. in a restaurant). Concurrent TV viewing and eating were operationalised as every 10-min block in which both $\mathrm{TV}$ viewing and eating were reported. The total time in minutes spent on (concurrent) TV viewing and eating was computed as the number of blocks in which the activity was reported multiplied by 10 (i.e. the duration of a block in minutes). The time spent on a single eating occasion was 
calculated as the number of consecutive blocks of eating multiplied by 10 . The total number of occasions (i.e. frequency) of concurrent TV viewing and eating was also counted. For descriptive purposes, the frequencies of eating with other media activities, and without media use, were also computed.

\section{Food-related TV content}

For TV content watched at the moment of broadcasting, respondents were asked to specify the title of the content. Content was coded as food-related if the main focus was food and cooking, such as in cooking shows and competitions or documentaries about restaurants and chefs (i.e. culinary content). Content that (potentially) displayed food but not as the main topic (e.g. a sitcom that takes place in a cafeteria) was coded as non-food related, as well as content focusing on the production of food rather than its consumption (e.g. a documentary about vegetable farming). Two coders independently judged all unique content $(n$ 922), which resulted in good interrater reliability $(\kappa=.78)$. Discrepancies were solved through discussion with a third coder. In total, 20 programmes were coded as food-related and 885 programmes were coded as non-food related. In addition, some content was coded as missing ( $n$ 17) because the title was not correctly specified.

\section{Demographic characteristics}

Respondents' age (20-34, 35-49, 50-64, 65+; merged into groups for anonymization reasons), gender (male/female) and educational level were assessed. Educational level was categorised as low (i.e. no education, primary education, lower general secondary education or lower vocational education), middle (higher general secondary education or intermediate vocational education) and high (i.e. higher vocational education or university degree).

\section{Additional variables}

For descriptive purposes, the time of the day, day of the week and the location of the respondent were registered for every 10-min block. Respondents also reported the device on which they watched media content.

\section{Analyses}

The data were first checked on the assumptions for conducting parametric statistical tests. Because the time use data were heavily skewed due to extreme scores, values of $-3 \mathrm{SD}$ and $+3 \mathrm{SD}$ from the mean on the dependent variables were excluded to prevent the influence of these extreme scores. Next, descriptive statistics were calculated on the prevalence of concurrent TV viewing and eating (RQ1), followed by $\chi^{2}$ tests and an independent-measures ANOVA to examine the influence of age, gender and education on the prevalence of concurrent TV viewing and eating (RQ2). Mixed-design ANOVA were then performed to test whether the average time spent on an eating occasion was longer while watching TV compared with without media use (H1a), whether the total time spent on eating was longer on days of concurrent TV viewing and eating compared with days of eating without media use (H1b) and whether the percentage of TV viewing time that was spent on concurrent eating was higher for food-related TV content compared with non-food related TV content (H2). Each of these analyses used the independent variable (the type of eating occasion in H1a and H1b, the type of TV content in H2) as within-subject variable. Age, gender and educational level were included as between-subjects variables to explore the role of demographic characteristics (RQ2).

\section{Results}

\section{Prevalence of concurrent $T V$ viewing and eating}

On average, respondents spent $171.76 \mathrm{~min} / \mathrm{d}$ watching TV $(\mathrm{SD}=111.19)$ and $71.07 \mathrm{~min}$ on eating $(\mathrm{SD}=30.96$; Table 2). Food was consumed in $4.1 \%$ of the total TV viewing time. Furthermore, $12 \cdot 1 \%$ of all eating occasions were with the TV on, $26.9 \%$ while engaging in other media activities (e.g. reading the newspaper, listening to radio and social media use) and $61.0 \%$ of the eating occasions took place without media use.

More than half of the respondents (51.3\%) reported concurrent TV viewing and eating at least 1 time during the $7 \mathrm{~d}$ of filling in the diary. On average, these respondents engaged in this behaviour 3.35 times $(\mathrm{SD}=2.66$ ) for a total of 97.65 $\min (\mathrm{SD}=79 \cdot 49)$ during this $7-\mathrm{d}$ period, which is approximately $14 \mathrm{~min} / \mathrm{d}$. Concurrent TV viewing and eating occurred on all days of the week, but often during the evening $(50.5 \%$ of the time spent on concurrent TV viewing and eating was during the evening), while being at home (97.0\%), using the TV set as device (90.5\%; Table 3).

Next, it was examined whether the prevalence of concurrent TV viewing and eating differed based on demographic characteristics (RQ2). $\chi^{2}$ tests showed no differences in the number of respondents who did ( $v$. did not) report concurrent TV viewing and eating based on age, $\chi^{2}(3$, $n$ 2292) $=3.46, P=0.325$, gender, $\chi^{2}(1, n 2292)=0.94$, $P=0.332$ or educational level, $\chi^{2}(2, n 2276)=1.54$, $P=0.464$ (Table 4). Furthermore, among respondents who did report concurrent TV viewing and eating at least once, an independent-measures ANOVA showed no differences in the amount of time (in minutes) spent on this behaviour based on age, $F_{3}, 1158=1.24, P=0.293$; gender, $F_{1}, 1158=0.76, P=0.385$ or educational level, $F_{2},{ }_{1158}=0 \cdot 12, P=0 \cdot 890$. Exploratory, non-preregistered analyses showed that a higher amount of time spent on concurrent TV viewing and eating was associated with a lower household income level, a lower number of household members and a lower average weekly working hours of the respondent (all $P_{S}<\cdot 0 \cdot 001$ ). Details regarding these analyses are available from the first author upon request. 
Table 2 Descriptive statistics of the prevalence of TV viewing and (concurrent) eating for concurrent TV viewers and eaters and for non-concurrent TV viewers and eaters

\begin{tabular}{|c|c|c|c|c|c|c|}
\hline & $\begin{array}{c}\text { Concurrent TV viewers and } \\
\text { eaters }(n=1175)\end{array}$ & SD & $\begin{array}{c}\text { Non-concurrent TV viewers and } \\
\text { eaters }(n=1117)\end{array}$ & SD & $\begin{array}{l}\text { Total sample } \\
(n=2292)\end{array}$ & SD \\
\hline TV viewing in min/d & $130 \cdot 43$ & $84 \cdot 23$ & 211.05 & $119 \cdot 21$ & $\begin{array}{c}171.76 \\
F_{1,2290}=346.47, \\
P<0.001\end{array}$ & $111 \cdot 19$ \\
\hline Eating in $\mathrm{min} / \mathrm{d}$ & $70 \cdot 85$ & $27 \cdot 97$ & $71 \cdot 30$ & $33 \cdot 84$ & $\begin{array}{c}71.07 \\
F_{1,2290}=0.12 \\
P=0.725\end{array}$ & 30.96 \\
\hline $\begin{array}{l}\% \text { of total viewing time } \\
\text { spent eating } \\
\% \text { of eating occasions. }\end{array}$ & $7.8 \%$ & & $0 \%$ & & $4.1 \%$ & \\
\hline While using TV & $23.3 \%$ & & $0 \%$ & & $12.1 \%$ & \\
\hline $\begin{array}{l}\text { While using other } \\
\text { media }\end{array}$ & $27.5 \%$ & & $26 \cdot 2 \%$ & & $26.9 \%$ & \\
\hline $\begin{array}{l}\text { While not using } \\
\text { media }\end{array}$ & $49.2 \%$ & & $73.8 \%$ & & $61.0 \%$ & \\
\hline
\end{tabular}

Table 3 Concurrent TV viewing and eating: day of the week, time of the day, location and device

\begin{tabular}{|c|c|c|c|}
\hline & \multicolumn{2}{|c|}{$\begin{array}{l}\text { Time spent on concurrent TV viewing } \\
\text { and eating in minutes, during the } 7 \mathrm{~d} \\
\text { of the diary }\end{array}$} & \multirow{2}{*}{$\begin{array}{c}\% \text { of the total time spent on concurrent } \\
\text { TV viewing and eating }\end{array}$} \\
\hline & Mean & SD & \\
\hline Total & $97 \cdot 65$ & $79 \cdot 49$ & $100 \%$ \\
\hline \multicolumn{4}{|l|}{ Day } \\
\hline Weekdays (Monday - Friday) & $70 \cdot 46$ & $66 \cdot 37$ & $70 \cdot 2 \%$ \\
\hline Weekend days (Saturday - Sunday) & $27 \cdot 19$ & 33.96 & $29.8 \%$ \\
\hline \multicolumn{4}{|l|}{ Time } \\
\hline Morning (06:00-11:59) & 24.41 & $42 \cdot 91$ & $25.0 \%$ \\
\hline Afternoon (12:00-17:59) & 23.46 & $37 \cdot 38$ & $24.0 \%$ \\
\hline Evening (18:00-23:59) & $49 \cdot 28$ & $53 \cdot 81$ & $50.5 \%$ \\
\hline Night $(00: 00-05: 59)$ & 0.50 & 5.49 & $0.5 \%$ \\
\hline \multicolumn{4}{|l|}{ Location } \\
\hline At home & 94.69 & 79.09 & $97.0 \%$ \\
\hline At someone else's home & 1.62 & $9 \cdot 61$ & $1.6 \%$ \\
\hline Elsewhere & 1.34 & 8.66 & $1.4 \%$ \\
\hline \multicolumn{4}{|l|}{ Device } \\
\hline TV set & 88.38 & $78 \cdot 74$ & $90.5 \%$ \\
\hline Pc/laptop & $4 \cdot 61$ & $24 \cdot 22$ & $4.7 \%$ \\
\hline Tablet & $2 \cdot 72$ & $16 \cdot 83$ & $2 \cdot 8 \%$ \\
\hline Smartphone & $1 \cdot 11$ & $13 \cdot 07$ & $1 \cdot 2 \%$ \\
\hline Other device & 0.70 & $6 \cdot 26$ & $0.7 \%$ \\
\hline Multiple devices & 0.13 & $2 \cdot 20$ & $0.1 \%$ \\
\hline
\end{tabular}

Results presented in this table are based on data of the respondents who reported concurrent TV viewing and eating at least once during the $7 \mathrm{~d}$ of the diary $(51.3 \%$ of the sample).

The activity of TV viewing and the time spent on (concurrent) eating

A mixed-design ANOVA was conducted to examine the average time (in minutes) spent on an eating occasion while watching TV $v$. without media use. Supporting $\mathrm{H1a}$, it was found that the average duration of an eating occasion was significantly longer while watching TV (Mean $=34 \cdot 38, \mathrm{SD}=16 \cdot 35)$ compared with without media use $\left(\right.$ Mean $=33.30, \mathrm{SD}=14.04$; Table 5), $F_{1}, \quad 1111=3.97$, $P=0.047, \eta_{p}^{2}=0.00$, although the effect size was very small. Investigating $\mathrm{RQ} 2$, no interactions were found with regard to age, $F_{3}, 1111=0.51, P=0.676$, gender,
$F_{1}, \quad{ }_{1111}=0.98, \quad P=0.322$ or educational level, $F_{2,1111}=0.34, P=0.714$.

Next, a mixed-design ANOVA was conducted on the daily total time (in minutes) spent on eating on days of concurrent TV viewing and eating $v$. days of eating without media use. In support of $\mathrm{H} 1 \mathrm{~b}$, it was found that a significantly longer total time was spent on eating on days of concurrent TV viewing and eating (Mean $=78 \cdot 24, \mathrm{sD}=36 \cdot 00$ ) compared with days of eating without media use (Mean $=63.37, \quad \mathrm{SD}=31.75), \quad F_{1}, \quad 830=93.76, \quad P<0.001$, $\eta_{p}^{2}=0 \cdot 10$, with a medium effect size. Regarding RQ2, no interactions were found regarding age, $F_{3}, \quad 830=0 \cdot 88$, 
Table 4 Concurrent TV viewing and eating: demographic characteristics

\begin{tabular}{|c|c|c|c|c|c|}
\hline & \multirow{3}{*}{$\begin{array}{c}\% \text { of sample that reported } \\
\text { concurrent TV viewing and } \\
\text { eating at least once }\end{array}$} & \multicolumn{4}{|c|}{$\begin{array}{l}\text { Time spent on concurrent TV viewing and eating in minutes } \\
\text { among respondents who reported this behaviour at least once }\end{array}$} \\
\hline & & \multicolumn{2}{|c|}{ Total (during the $7 \mathrm{~d}$ ) } & \multicolumn{2}{|c|}{ Average/d } \\
\hline & & Mean & SD & Mean & SD \\
\hline \multicolumn{6}{|l|}{ Age } \\
\hline 20-34 years old & $49.4 \%$ & $96 \cdot 34$ & $82 \cdot 20$ & $13 \cdot 76$ & 11.74 \\
\hline 35-49 years old & $49.4 \%$ & 93.43 & $79 \cdot 80$ & $13 \cdot 35$ & 11.40 \\
\hline 50-64 years old & $53.0 \%$ & 97.02 & $76 \cdot 63$ & $13 \cdot 86$ & $10 \cdot 95$ \\
\hline $65+$ years old & $53.7 \%$ & $106 \cdot 16$ & $80 \cdot 71$ & $15 \cdot 17$ & 11.53 \\
\hline \multicolumn{6}{|l|}{ Gender } \\
\hline Male & $50 \cdot 1 \%$ & $96 \cdot 00$ & 80.05 & 13.71 & 11.44 \\
\hline Female & $52 \cdot 1 \%$ & 98.85 & $79 \cdot 41$ & $14 \cdot 12$ & $11 \cdot 34$ \\
\hline \multicolumn{6}{|l|}{ Educational level } \\
\hline Low & $53.6 \%$ & $100 \cdot 85$ & $80 \cdot 05$ & 14.41 & 11.44 \\
\hline Middle & $51.5 \%$ & 98.52 & 80.60 & 14.07 & 11.51 \\
\hline High & $50 \cdot 1 \%$ & 96.03 & 79.00 & $13 \cdot 72$ & 11.29 \\
\hline
\end{tabular}

Table 5 Results of the hypotheses tests (means and SD's)

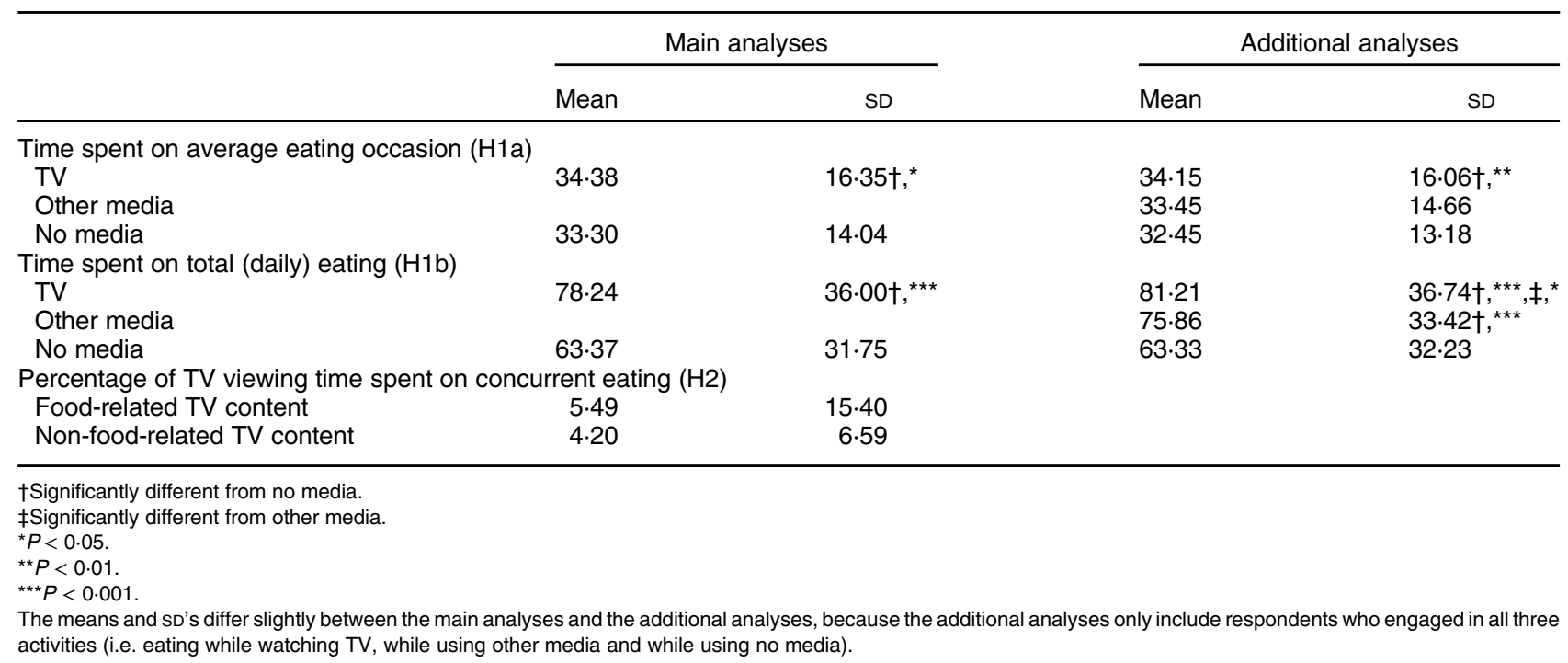

$P=0.450$, gender, $F_{1,830}=0.13, P=0.723$ or educational level, $F_{2,830}=0 \cdot 84, P=0.431$.

Exploratory, non-preregistered analyses were conducted to investigate the possibility that the longer total time spent on eating on days of concurrent TV viewing and eating ( $v$. days of eating without media use, H1b) was merely explained by differences in the amount of TV viewing between those days, instead of eating while watching TV per SE. The analysis for H1b was therefore re-run in a subsample of respondents $(n 161)$ who showed an approximately similar total time spent on TV viewing on days of concurrent TV viewing and eating and on days of eating without media use (i.e. a maximum difference of $30 \mathrm{~min}$, Mean $=-00 \cdot 04, \mathrm{SD}=1.83)$. With this subsample, similar results were obtained for $\mathrm{H} 1 \mathrm{~b}, F_{1,153}=18.23$, $P<0.001, \eta_{p}^{2}=0.11$. It is therefore deemed implausible that the amount of TV viewing in general accounted for the findings reported for $\mathrm{H} 1 \mathrm{~b}$.

\section{Additional analyses on other media activities}

Additional analyses were conducted to explore whether these findings were specific for TV viewing, or also held true for media activities other than TV viewing (e.g. reading, social media use). To test this, the time spent on an eating occasion was compared for three types of activities: while watching TV, while engaging in other media activities and without using media. The overall test was significant, $F_{1.96}$, 1806.08 $=4.61, \quad P=0.011, \quad \eta_{p}^{2}=0.01$. Bonferroni-corrected post hoc tests showed that only the difference between TV $v$. no media was significant $\left(P=0.007, \mathrm{M}_{\text {diff }}=1.79\right.$, $\mathrm{SE}=0.59$; Table 5). There was no significant difference between other media $v$. no media $\left(P=0.301, \mathrm{M}_{\text {diff }}=0.92\right.$, 
$\mathrm{SE}=0.56)$, nor between TV $v$. Other media $(P=0.487$, $\left.\mathrm{M}_{\text {diff }}=0.88, \mathrm{SE}=0.63\right)$. Similar analyses were conducted for the total time spent on eating. The overall test was significant, $F_{1.98,1128.05}=47.07, P<0.001, \eta_{p}^{2}=0.08$. Bonferronicorrected post hoc tests showed that all means were significantly different from each other. Compared with days of eating without media use, the total time spent on eating was longer on days of eating while using other media $\left(P<0.001, \mathrm{M}_{\mathrm{diff}}=12.58, \mathrm{sE}=1 \cdot 75\right)$, and even longer on days of eating while watching TV (compared with no media: $P<0.001, \quad \mathrm{M}_{\mathrm{diff}}=17.39, \quad \mathrm{SE}=1.88 ;$ compared with other media: $\left.P=0.037, \mathrm{M}_{\mathrm{diff}}=4.81, \mathrm{sE}=1.92\right)$. Altogether, these additional findings show that even though eating while using media may generally be associated with an increased time spent eating, this is particularly the case for TV viewing.

\section{Food-related TV content and concurrent eating}

In total, 162 respondents $(7 \cdot 1 \%)$ reported watching foodrelated TV content at least once, and on average, these respondents watched such content for $90.62 \mathrm{~min}$ during the $7 \mathrm{~d}(\mathrm{SD}=97.97)$, or approximately $13 \mathrm{~min} / \mathrm{d}$. A mixed-design ANOVA on the percentage of TV viewing time that was spent on concurrent eating showed, in contrast to $\mathrm{H} 2$, no differences between food-related (Mean $=5 \cdot 49, \mathrm{SD}=15 \cdot 40)$ and non-food-related TV content $\left(\right.$ Mean $=4.20, \mathrm{sD}=6.59$; Table 5), $F_{1,151}=0.59, P=0.445$. Regarding RQ2, no interactions were found regarding age, $F_{3,151}=0.53, P=0.664$, gender $F_{1,151}=0.13, P=0.724$ or educational level, $F_{2,151}=0.95, P=0.388$.

\section{Discussion}

The current study investigated concurrent TV viewing and eating in a naturalistic setting among a sample of the general population of adults in the Netherlands. Secondary data analyses were conducted of a 7-d time use survey to examine the prevalence of concurrent TV viewing and eating, as well two potential explanations for increased eating associated with TV viewing: the general activity of TV viewing and exposure to food on TV. Further, to gain insight into whom might be particularly susceptible to (the influences of) concurrent TV viewing and eating, the role of demographic characteristics was also explored. Results showed that eating while watching TV is relatively common. More than half of the respondents $(51.3 \%)$ reported concurrent TV viewing and eating at least once - but on average 3.35 times - during the 7-d diary period. Furthermore, the amount of concurrent TV viewing and eating was not related to age, gender and educational level. To date, knowledge on the prevalence of concurrent TV viewing and eating was largely absent in the general population of adults. The current study provides evidence that TV viewing and eating frequently co-occur, irrespective of demographic characteristics. This suggests that eating while watching TV could indeed play a role in explaining the association between TV viewing and increased eating ${ }^{(1,12)}$. Further findings from the current study emphasise this potential impact of eating while watching TV, as it was found that the average time spent on an eating occasion was longer when food was consumed in front of the TV than when food was consumed without using media. In addition, it appeared that this longer duration was not compensated for at another moment during the day, as the total time spent on eating was longer on days of concurrent TV viewing and eating compared with days of eating without simultaneously using media. Taken together with findings from prior research in laboratory settings and among student samples that reported increased energy intake resulting from concurrent TV viewing and eating ${ }^{(9,13,23,24)}$, and other research showing that the time spent eating predicts energy intake $\mathrm{e}^{(20,26-28)}$, it seems likely that concurrent TV viewing and eating contribute to increased food consumption. It should be noted that the effect size for the time spent on an eating occasion was very small. In absolute terms, the average eating occasion took just more than 1 min longer while watching TV compared with without media use. However, when this occurs on a frequent basis - as shown by the data on the prevalence of concurrent TV viewing and eating - this could have a significant impact on overall eating behaviour, especially given the finding that eating in front of the TV does not appear to be compensated for but is rather associated with an overall increased time spent eating during the day. No differences were observed in the time spent on eating while watching food-related (i.e. culinary) compared with non-food-related TV content. This finding contrasts with the notion that exposure to food on TV may be an important explanation for increased eating associated with TV viewing ${ }^{(5,7,40)}$ and is further inconsistent with several experimental studies empirically supporting this notion $^{(8,10,34)}$. Moreover, it was found that relatively few respondents ( $7 \cdot 1 \%$ of the sample) watched culinary TV content. This may appear to indicate the small influence of exposure to food cues on TV, but on a daily basis people are likely also exposed to a range of other food cues on TV (e.g. in commercials or in movies). The joint impact of exposure to this variety of food cues on people's eating behaviour could therefore be stronger than the current study seems to suggest and should therefore be further investigated. However, it should also be noted that other studies did not find evidence for the influence of food-related TV content on eating behaviour either ${ }^{(35-37,48)}$. It is therefore also possible that exposure to food cues may not have a strong direct impact on (concurrent) eating. However, such (often unhealthy) food cues may still communicate norms about eating as form of entertainment rather than focusing on its nutritional value, which could subsequently impact one's overall diet ${ }^{(5,31)}$. The impact of this - and perhaps other indirect influences is worth investigating.

Together, results from the present study suggest that associations between TV viewing and increased (concurrent) eating may be explained by the activity of TV viewing, and not 
necessarily by exposure to food cues in TV content. A plausible explanation for these findings is distraction. Distracted eating, for example during TV viewing, reduces the availability of attentional resources for internal signals that normally regulate the end of the meal, such as satiety ${ }^{(5,6,49)}$. Instead, one may use external signals to a greater extent (e.g. the end of a TV show), which could explain the longer duration of an eating occasion in front of the TV relative to no use of media ${ }^{(20)}$. Distraction may further explain an increased overall time spent on eating. Previous laboratory research found that eating with ( $v$. without) the TV on resulted in an underestimation of the amount eaten, as well as in a less vividly experienced eating episode, and this subsequently resulted in a higher energy intake during a second eating session later on the day ${ }^{(9,23,24)}$. Distracted eating has also been found to result in smaller decreases in satiety compared with nondistracted eating, which may similarly contribute to increased eating later ${ }^{(25)}$. The higher overall time spent on eating on days of concurrent TV viewing and eating ( $v$. days of no concurrent TV viewing and eating) suggests that distraction could be a plausible explanation for the findings in the current study. Moreover, additional findings of the current study showed that eating while engaging in other media activities (e.g. reading, social media use) was also related to an increased time spent on eating, but not as much as TV viewing. This finding, also reported in previous experimental research ${ }^{(19,50)}$, is further in line with this explanation of distraction. TV content is often narrative-based, and narrative media content more easily facilitates transportation (the experience of immersion in another world) compared with other, non-narrative media content $^{(51)}$. TV viewing may therefore be particularly distracting ${ }^{(50)}$. Investigating differences in the distractive potential between other types of media activities (i.e. reading a newspaper $v$. checking social media updates) was beyond the scope of the present research but is worthy of future investigation. Although distraction seems a plausible explanation for the findings of the current study, other potential mechanisms may account for the relationship between TV viewing and increased (concurrent) eating as well, such as learned associations between these two behaviours resulting from repeatedly pairing TV viewing and eating in the past ${ }^{(4,21)}$ and a positive mood induced by TV viewing ${ }^{(6,22)}$. Future research should investigate to what extent the findings of the current study can be explained by distraction, and/or potential other mechanisms.

\section{Limitations}

Because the data were collected as part of a more general study on time use, the current study is limited with regard to some of the measurements. First, the measure of eating was limited to the duration of eating, and no information was obtained on the amount and type of food consumed. This limits the strength of the conclusions, because energy intake is ultimately most relevant in terms of implications for overweight and obesity, and a longer time spent on eating does not necessarily reflect a higher energy intake. Although prior research indicates that more time spent on eating is related to increased energy intake ${ }^{(20,26,27)}$, this cannot be verified with the current data. In addition, only activities that lasted at least 5 min were reported, thus likely not all eating occasions (e.g. eating one cookie) were registered. More generally, the use of (partially) retrospective diaries could have caused some misreporting of behaviour. Future research should aim to measure food intake (and TV viewing) more precisely and in the moment, for example by using Ecological Momentary Assessment ${ }^{(52)}$, to improve understanding of the potential impact of concurrent TV viewing and eating in relation to weight gain. Second, the assessment of exposure to food cues in TV content was limited to TV programmes related to food and cooking. However, food cues also appear in TV commercials, or more subtly in nonfood-related TV content (e.g. in an episode of a sitcom that takes place in a restaurant). In future research, exposure to food on TV should be measured more precisely, by taking into account various types of food cues on TV. Third, although the current study explored the influence of individual differences in demographic variables (i.e. age, gender and educational level), other potentially important individual difference variables were not assessed. For instance, BMI and eating restraint (i.e. chronic dieting) have previously been found to influence eating behaviour in response to food cues in lab settings ${ }^{(53,54)}$. There is also evidence that the amount of attention allocated to TV content is positively associated with $\mathrm{BMI}^{(55)}$, which suggests that if increased eating associated with TV viewing is a result of distraction, this might be particularly problematic for individuals with overweight. The influence of these and other potential individual differences could be further explored in future research. Even though the cross-sectional design is a strength of the current study as respondents were free to follow their natural behavioural patterns of TV viewing and eating, it may also be considered a limitation as no causal conclusions can be drawn. The use of within-subjects measures did allow to rule out some alternative explanations, for instance that individuals who frequently eat in front of the TV are more inclined towards living a less healthy lifestyle and therefore spend much time on eating ${ }^{(56)}$. However, a third, intra-individual variable might still account for the associations between TV viewing and eating (e.g. variations in the amount of leisure time, eating alone $v$. with others). A suggestion for future research would be to adopt an intervention study (including a control group) aimed at reducing eating in front of the TV. Such a study could causally test the observed relationships in a naturalistic setting.

\section{Conclusions}

Concurrent TV viewing and eating were relatively commonly reported, and this behaviour was associated with a longer time spent on a single occasion of eating, as well as with a 
longer total time spent on eating during the day. Watching food-related (i.e. culinary) TV content was not related to the time spent on concurrent eating. Extending prior research conducted in laboratory contexts, the current findings from a naturalistic setting suggest that eating while watching TV may contribute to increased immediate and overall food intake, possibly by drawing attention away from eating. The current study therefore provides further evidence that eating while watching TV is a relevant factor to take into account in the battle against obesity.

\section{Acknowledgements}

Acknowledgements: (1) The authors thank Robert Alblas and Aimee Diepgrond for their valuable contributions (resp. data restructuring, coding work) to this article and (2) the data used in this article were collected by GfK Market Research for a research project commissioned by the Netherlands Institute for Social Research (Sociaal en Cultureel Planbureau; SCP), Stichting KijkOnderzoek (SKO), Nationaal Luister Onderzoek (NLO), Nationaal Onderzoek Multimedia (NOM) and Platform Media Adviesbureaus (PMA). Financial support: This research received no specific grant from any funding agency, commercial or not-for-profit sectors. Conflict of interest: There are no conflicts of interest. Authorship: Conceptualisation and methodology: all authors. Data analysis: M.C.A. Writing original draft preparation: M.C.A. Editing draft paper: all authors. Ethics of human subject participation: For the current study secondary data analyses were conducted based on data collected by GfK Market Research. Written informed consent was obtained from all subjects, and data usage is in accordance with the privacy regulations laid down in the General Data Protection Regulation (GDPR).

\section{References}

1. Hu FB, Li TY, Colditz GA et al. (2003) Television watching and other sedentary behaviors in relation to risk of obesity and type 2 diabetes mellitus in women. $\mathrm{J} \mathrm{Am} \mathrm{Med} \mathrm{Assoc}$ 289, 1785-1791

2. Roda C, Charreire H, Feuillet T et al. (2016) Lifestyle correlates of overweight in adults: a hierarchical approach (the SPOTLIGHT project). Int J Behav Nutr Phys Act 13, $1-12$.

3. Helajärvi H, Rosenström T, Pahkala K et al. (2014) Exploring causality between TV viewing and weight change in young and middle-aged adults. The cardiovascular risk in Young Finns study. PLoS One 9, 1-11.

4. Marsh S, Mhurchu CN \& Maddison R (2013) The non-advertising effects of screen-based sedentary activities on acute eating behaviours in children, adolescents, and young adults. A systematic review. Appetite 71, 259-273.
5. Boulos R, Vikre EK, Oppenheimer S et al. (2012) ObesiTV: how television is influencing the obesity epidemic. Physiol Behav 107, 146-153.

6. Braude L \& Stevenson RJ (2014) Watching television while eating increases energy intake. Examining the mechanisms in female participants. Appetite 76, 9-16.

7. Foster JA, Gore SA \& West DS (2006) Altering TV viewing habits: an unexplored strategy for adult obesity intervention? Am J Health Behav 30, 3-14.

8. Harris JL, Bargh JA \& Brownell KD (2009) Priming effects of television food advertising on eating behavior. Health Psychol 28, 404-413.

9. Mittal D, Stevenson RJ, Oaten MJ et al. (2011) Snacking while watching TV impairs food recall and promotes food intake on a later TV free test meal. Appl Cogn Psychol 25, 871-877.

10. Bodenlos JS \& Wormuth BM (2013) Watching a food-related television show and caloric intake. A laboratory study. Appetite 61, 8-12.

11. Meyer A-M, Evenson KR, Couper DJ et al. (2008) Television, physical activity, diet, and body weight status: the ARIC cohort. Int J Behav Nutr Phys Act 5, 1-14.

12. Bowman SA (2006) Television-viewing characteristics of adults: correlations to eating practices and overweight and health status. Prev Chronic Dis 3, 1-11.

13. Stroebele N \& De Castro JM (2004) Television viewing is associated with an increase in meal frequency in humans. Appetite 42, 111-113.

14. Ellithorpe ME, Eden A, Hahn L et al. (2019) Meal-concurrent media use is associated with increased dietary intake with no evidence of next meal compensation in free-living adults. Obesity 27, 1418-1422.

15. Gore SA, Foster JA, DiLillo VG et al. (2003) Television viewing and snacking. Eat Behav 4, 399-405.

16. McNaughton SA, Pendergast FJ, Worsley A et al. (2020) Eating occasion situational factors and sugar-sweetened beverage consumption in young adults. Int J Behav Nutr Phys Act 17, $1-12$

17. Cleland VJ, Schmidt MD, Dwyer T et al. (2008) Television viewing and abdominal obesity in young adults: is the association mediated by food and beverage consumption during viewing time or reduced leisure-time physical activity? Am J Clin Nutr 87, 1148-1155.

18. Bellisle F, Dalix AM \& Slama G (2004) Non food-related environmental stimuli induce increased meal intake in healthy women: comparison of television viewing $v$. listening to a recorded story in laboratory settings. Appetite 43, 175-180.

19. Blass EM, Anderson DR, Kirkorian HL et al. (2006) On the road to obesity: television viewing increases intake of high-density foods. Physiol Behav 88, 597-604.

20. Hetherington MM, Anderson AS, Norton GNM et al. (2006) Situational effects on meal intake: a comparison of eating alone and eating with others. Physiol Behav 88, 498-505.

21. Chaput J-P, Klingenberg L, Astrup A et al. (2011) Modern sedentary activities promote overconsumption of food in our current obesogenic environment. Obes Rev 12, 12-20.

22. Köster EP \& Mojet J (2015) From mood to food and from food to mood: a psychological perspective on the measurement of food-related emotions in consumer research. Food Res Int 76, 180-191.

23. Higgs S (2015) Manipulations of attention during eating and their effects on later snack intake. Appetite 92, 287-294.

24. Higgs S \& Woodward M (2009) Television watching during lunch increases afternoon snack intake of young women. Appetite 52, 39-43.

25. Brunstrom JM \& Mitchell GL (2006) Effects of distraction on the development of satiety. Br J Nutr 96, 761-769.

26. Pliner P, Bell R, Hirsch ES et al. (2006) Meal duration mediates the effect of "social facilitation" on eating in humans. Appetite 46, 189-198. 
27. Stroebele N \& De Castro JM (2006) Listening to music while eating is related to increases in people's food intake and meal duration. Appetite 47, 285-289.

28. Bertrand M \& Schanzenbach DW (2009) Time use and food consumption. Am Econ Rev Pap Proc 99, 170-176.

29. Kolodinsky JM \& Goldstein AB (2009) Time use and food pattern influences on obesity. Obesity 19, 2327-2335.

30. Boyce T (2007) The media and obesity. Obes Rev 8, Suppl. 1, 201-205.

31. Dickinson R (2000) Food and eating on television: impacts and influences. Nutr Food Sci 30, 24-29.

32. De Solier I (2005) TV dinners: culinary television, education and distinction. Continuum 19, 465-481.

33. Pinel JPJ, Assanand S \& Lehman DR (2000) Hunger, eating, and ill health. Am Psychol 55, 1105-1116.

34. Koordeman R, Anschutz DJ, Van Baaren RB et al. (2010) Exposure to soda commercials affects sugar-sweetened soda consumption in young women. An observational experimental study. Appetite 54, 619-622.

35. Bellisle F, Dalix AM, Airinei G et al. (2009) Influence of dietary restraint and environmental factors on meal size in normalweight women. A laboratory study. Appetite 53, 309-313.

36. Alblas MC, Mollen S, Fransen ML et al. (2021) See the cake and have it too? Investigating the effect of watching a TV cooking show on unhealthy food choices. Physiol Behav 236, 113409.

37. Boyland EJ, Burgon RH \& Hardman CA (2017) Reactivity to television food commercials in overweight and lean adults: physiological, cognitive and behavioural responses. Physiol Behav 177, 182-188.

38. Anschutz DJ, Engels RCME, Van der Zwaluw CS et al. (2011) Sex differences in young adults' snack food intake after food commercial exposure. Appetite 56, 255-260.

39. Wonderlich-Tierney AL, Wenzel KR, Vander Wal JS et al. (2013) Food-related advertisements and food intake among adult men and women. Appetite 71, 57-62.

40. Scully M, Dixon H \& Wakefield M (2016) Association between commercial television exposure and fast-food consumption among adults. Public Health Nutr 12, 105-110.

41. Thomson M, Spence JC, Raine K et al. (2008) The association of television viewing with snacking behavior and body weight of young adults. Am J Health Promot 22, 329-335.

42. De Backer CJS \& Hudders L (2016) Look who's cooking. Investigating the relationship between watching educational and edutainment TV cooking shows, eating habits and everyday cooking practices among men and women in Belgium. Appetite 96, 494-501.
43. Boswell RG \& Kober H (2016) Food cue reactivity and craving predict eating and weight gain: a meta-analytic review. Obes Rev 17, 159-177.

44. Mills SDH, Tanner LM \& Adams J (2013) Systematic literature review of the effects of food and drink advertising on food and drink-related behaviour, attitudes and beliefs in adult populations. Obesity 14, 303-314.

45. Devaux M, Sassi F, Church J et al. (2011) Exploring the relationship between education and obesity. OECD J Econ Stud 1, 121-159.

46. Chen C, Ye Y, Zhang Y et al. (2019) Weight change across adulthood in relation to all cause and cause specific mortality: prospective cohort study. BMJ 367, 15584.

47. Wennekers A, Bassler A, Sonck N et al. (2017) Media:time: a new time-use survey method to capture today's media use. Surv Pract 10, 1-9.

48. Villani AM, Egan T, Keogh JB et al. (2015) Attitudes and beliefs of Australian adults on reality television cooking programmes and celebrity chefs. Is there cause for concern? Descriptive analysis presented from a consumer survey. Appetite 91, 7-12.

49. Robinson E, Aveyard P, Daley A et al. (2013) Eating attentively: a systematic review and meta-analysis of the effect of food intake memory and awareness on eating. $\mathrm{Am} \mathrm{J}$ Clin Nutr 97, 728-742.

50. Lyons EJ, Tate DF \& Ward DS (2013) The better the story, the bigger the serving: narrative transportation increases snacking during screen time in a randomized trial. Int J Behav Nutr Phys Act 10, 1-6.

51. Green MC, Brock TC \& Kaufman GF (2004) Understanding media enjoyment: the role of transportation into narrative worlds. Commun Theory 14, 311-327.

52. Maugeri A \& Barchitta M (2019) A systematic review of ecological momentary assessment of diet: implications and perspectives for nutritional epidemiology. Nutrients $\mathbf{1 1}$, $1-24$.

53. Van den Akker K, Stewart K, Antoniou EE et al. (2014) Food cue reactivity, obesity, and impulsivity: are they associated? Curr Addict Reports 1, 301-308.

54. Polivy J \& Herman CP (2017) Restrained eating and food cues: recent findings and conclusions. Curr Obes Rep $\mathbf{6}$, 79-85.

55. Bickham DS, Blood EA, Walls CE et al. (2013) Characteristics of screen media use associated with higher BMI in young adolescents. Pediatrics 131, 935-941.

56. Coon KA, Goldberg J, Rogers BL et al. (2001) Relationships between use of television during meals and children's food consumption patterns. Pediatrics 107, e7. 